\title{
MALİ KURALLARIN KAVRAMSAL ÇERÇEVESİ VE UYGULAMALARIN AMPIRIKK SONUÇLARI
}

Merve YOLAL EROĞLU1

Atıf/C: Yolal Eroğlu, M. (2018). Mali kuralların kavramsal çerçevesi ve uygulamaların ampirik sonuçları. Hitit Üniversitesi Sosyal Bilimler Enstitüsü Dergisi, 11(3), 2366-2381. doi: 10.17218/hititsosbil.431178

Özet: Mali kurallar literatürde genel olarak gelir, harcama, bütçe ve borçlanma olmak üzere temel mali değişkenlerin birtakım sayısal sınırlamalara tabi olması şeklinde ifade edilmektedir. Küresel anlamda kullanım alanı bulan ve yapılan ampirik araştırmalar sonucunda da önemi anlaşılan mali kurallara; mali şeffaflığın azalması, mali disiplinsizlik ve mali sürdürülebilirliğin ortadan kalkması, politikacıların oy maksimizasyonu amacıyla maliye politikası araçlarını keyfi olarak kullanması sonucunda kamu borçlarının hızla artması gibi nedenlerle başvurulmaktadır. Bu çalışmanın amacı, maliye politikası uygulamalarına yönelik getirilen sınırlandırmalardan birisi olan mali kural kavramının tanımını, uygulanma nedenlerini ve özelliklerini ele alarak, mali kural uygulamalarının ampirik sonuçlarını değerlendirmektir.

Anahtar Kelimeler: Mali Kurallar, Kurala Dayalı Maliye Politikası, Denk Bütçe Kuralı, Harcama Kuralı The Conceptual Framework of Financial Rules and Empirical Results of
Applications

Citation/( : Yolal Eroğlu, M. (2018). Conceptual framework of financial rules and empirical results of applications. Hitit University Journal of Social Sciences Institute, 11(3), 2366-2381. doi: 10.17218/hititsosbil.431178

Abstract: Fiscal rules generally refer to some quantative restrictions on the basic financial variables such as income, expenditure, budget and borrowing. Fiscal rules have been applied on a global scale and draw attention as a result of numerous empirical researches. Financial rules are applied due to the decrease of fiscal transparency, the elimination of fiscal discipline and financial sustainability, and the rapid increase of public debts as a result of arbitrary use of fiscal policy instruments for the purpose of vote maximization. The aim of this study is to examine the definition, the implementation and the characteristics of the fiscal rule as being one of the limitations imposed on fiscal policy practices. At the same time, focus will be placed on evaluating the empirical results of fiscal rule practices.

Keywords: Fiscal Rules, Rule-Based Fiscal Policy, Budget Balance Rule, Expenditure Rule

1. GİRIŞ

Mali kurallar; bütçe, borçlanma, harcama ve gelir gibi birtakım göstergelere getirilen sınırlandırmalardır. 1970'li ve 1980'li yıllarda biriken kamu borçları ve para birliğinin kural tabanlı çerçevelerle desteklenmesi gerekliliği sonucunda hükümetler bazı sayısal kısıtlamalara gitmek zorunda kalmıştır. 1990 yılında yalnızca beş ülke (Almanya, Endonezya, Japonya, Lüksemburg ve Birleşik Devletler) merkezi hükümet düzeyinde mali kurallara sahiplerken, günümüzde çoğu devlet mali disiplini, mali istikrarı ve makro-ekonomik hedefleri gerçekleştirilebilmek amacıyla çeşitli mali kurallara başvurmaktadır. Mali kurallar çoğunlukla bütçe değişkenlerini sınırlamak için kullanılmaktadır. Çünkü bütçe değişkenleri hem harcamaları hem vergileri hem de bu ikisine bağlı olarak gelişen borçlanmayı yönlendirmektedir. Bu yolla,

Makale Geliş Tarihi: 6.6.2018

Makale Kabul Tarihi: 11.12 .2018

${ }^{1}$ Arş. Gör., Dokuz Eylül Üniversitesi, İktisadi ve İdari Bilimler Fakültesi, Maliye Bölümü, merve.yolal@deu.edu.tr, http://orcid.org/0000-0001-5980-5610 
ihtiyari maliye politikalarını sınırlandırarak nesiller arasında borç yükünün adil dağılımını gerçekleştirmekte, kamu bütçesinin şeffaflığını artırmakta, hükümetin etkinliğini ve hesap verebilirliğini sağlamaktadır.

Dünyada küresel bir hız kazanarak popülerliği artan ve uygulanmaya devam edilen mali kurallar; ülkelerin içinde bulundukları ekonomik konjonktüre, kurumsal kültürlerine ve hedeflerine göre belirlenmektedir. Mali kurallara yönelik olarak yapılan ampirik çalışmalar ise, ulusal mali kuralların genel olarak gelişmiş mali performans ile ilişkili olduğuna işaret etmektedir. Çalışmada kamu maliyesi literatüründe mali kurallara yönelik yapılmış olan birtakım tanımlara, mali kuralların oluşturulma gerekçelerine, mali kural türlerine, mali kuralların sahip olduğu fonksiyonlara ve özelliklere ve mali kurallara ilişkin yapılmış olan ampirik araştırmalar ve sonuçlarına yer verilmiştir. Bu bağlamda çalışma dört bölümden oluşmaktadır. İlk bölümde kurala dayalı ekonomi politikası bağlamında mali kurallara yönelik açıklamalar yapılacaktır. İkinci bölümde mali kuralların oluşturulma gerekçelerine ve sahip oldukları özelliklere yer verilecektir. Üçüncü bölüme gelindiğinde, mali kurallar türlerine göre ayrılarak denk bütçe kuralları, harcama ve gelir kuralları, borçlanma kuralları olmak üzere ayrı ayrı incelenecektir. Son bölümde ise, mali kurallar ile ilgili yapılmış çeşitli ampirik çalışmalar ve sonuçlarına yer verilerek, sonuç kısmında genel bir değerlendirme yapılacaktır.

\section{MALİ KURALLARIN TANIMI}

Politikacıların maliye politikası araçlarını kullanma üzerindeki yetkilerinin yasal ve anayasal sınırlamalara tabi tutularak uygulanmasını sağlayan yaklaşıma kurallara dayalı maliye politikası adı verilmektedir. Kurallara dayalı maliye politikasının en önemli özelliği, politikacıları ekonomi politikası araçlarını kullanırken birtakım keyfi uygulamalarını sınırlandırması ve belirlenen kurallar çerçevesinde yetkilerini kullanma hakkı vermesidir. Dolayısıyla kurala dayalı ekonomi politikası; politik çıkarları korumak uğruna yapılacak olan uygulamaların önüne geçerek, politikacıların sahip olduğu yetkilerini suiistimal etmelerini önlemekte ve bu sayede ekonomik öngörülebilirliği kolaylaştırmaktadır. Ayrıca mali kurallar mali disiplinin sağlanarak yasal veya anayasal düzenlemeler ile gerekli reformların yapılmasına da öncülük etmektedir.

Kurala dayalı ekonomi politikaları kapsamında bilhassa 1970'li ve 1980'li y1llardan sonra maliye politikalarına yönelik kuralların önemi fark edilmiştir. Maliye politikası kuralı, makroekonomik anlamda, mali performansın bir göstergesi olarak tanımlanan maliye politikası üzerinde kalıc1 kısıtlamalar olarak tanımlanmaktadır. Dar bir tanımlamada ise mali kurallar; bütçe öncesi (planlanan) ve bütçe sonrası (gerçekleşen) uyumsuzluğun birtakım yaptırımlara tabi olması anlamına gelmektedir. Örneğin, bazı ABD eyaletlerinde bütçe açığı ve borçlanma limitlerinin planlananın üzerinde gerçekleşmesi durumunda adli veya mali yaptırımlar uygulanmaktadır (Kopits ve Symansky, 1998, s. 2). Hallerberg'e göre mali kurallar, bütçesel karar alma ve uygulamada yol gösteren davranışsal ya da yasal normlardır (Hallerberg ve diğerleri, 2004, s. 15). Başka bir tanıma göre, mali kurallar bütçe politikası, borçlanma, harcama veya vergilendirme gibi bir mali göstergeye belirli bir sınır koyan yasal veya anayasal kısıtlamalardır (Kennedy ve diğerleri, 2001, s. 238). Mali kural kavramına ilişkin literatürde çeşitli tanımlar bulunmakla birlikte, öz itibariyle; bütçe açığı, harcama, borçlanma ve gelir olmak üzere bazı mali değişkenler üzerine getirilen sınırlandırmalar şeklinde tanımlanmaktadır. Diğer bir deyişle, mali kurallar harcama ve gelir programları ile ilgili kararları sınırlamak için, politika yapıcıların "ellerini bağlamaya" çalışarak "açık eğilimini" azaltmayı ve mali disiplini teşvik etmeyi amaçlayan yasal anlaşmalardır (Bergman ve diğerleri, 2016, s. 2). Mali kurallar; hedef değişken, planlama süresi, 
kapsamı ve yasal temeli bakımından ülkeler arasında farklılıklar göstermektedir. Belirtilen bu farklılıklar çeşitli ülkeler açısından Tablo 1'de gösterilmektedir,

Tablo 1. Uluslararası Mali Kuralların Karşılaştırması

\begin{tabular}{|c|c|c|c|c|}
\hline Ülke & Kuralın Türü/Amacı & $\begin{array}{l}\text { Planlama } \\
\text { Süresi }\end{array}$ & Kapsamı & Yasal Temeli \\
\hline İsrail & Açık ve harcama tavanları & Çok yıllı & MY & Kanun \\
\hline Danimarka & Yapisal bütçe dengesi & Çok y1llı & MY & $\begin{array}{l}\text { Politik } \\
\text { anlaşma }\end{array}$ \\
\hline Estonya & $\begin{array}{l}\text { Bütçe dengesi } \\
\text { Gelirin yüzdesi olarak borç }\end{array}$ & $\begin{array}{l}\text { Çok y1llı } \\
\text { Y1llık }\end{array}$ & $\begin{array}{l}\text { MY } \\
\text { YY }\end{array}$ & $\begin{array}{l}\text { Politik } \\
\text { anlaşma } \\
\text { Kanun }\end{array}$ \\
\hline Finlandiya & $\begin{array}{l}\text { Bütçe dengesi } \\
\text { GSYİH yüzdesi olarak borç }\end{array}$ & $\begin{array}{l}\text { Çok y1ll1 } \\
\text { Çok y1ll1 }\end{array}$ & $\begin{array}{l}\text { MY } \\
\text { YY MY }\end{array}$ & $\begin{array}{l}\text { Politik } \\
\text { anlaşma } \\
\text { Kanun } \\
\text { Politika } \\
\text { anlaşma }\end{array}$ \\
\hline Fransa & Altın kural & Y1llik & $\mathrm{YY}$ & Kanun \\
\hline Litvanya & $\begin{array}{l}\text { Net borçlanma tavanı } \\
\text { Bütçe dengesi }\end{array}$ & $\begin{array}{l}\text { Y1ll1k } \\
\text { Y1ll1k }\end{array}$ & $\begin{array}{l}\text { MY } \\
\text { YY }\end{array}$ & $\begin{array}{l}\text { Kanun } \\
\text { Kanun }\end{array}$ \\
\hline Hollanda & Harcama tavanı & Çok y1llı & MY & $\begin{array}{l}\text { Koalisyon } \\
\text { anlaşması }\end{array}$ \\
\hline Polonya & GSYİH yüzdesi olarak borç & Y1ll1k & MY & Anayasa \\
\hline Slovakya C. & Gelirin yüzdesi olarak borç & Y1ll1k & $\mathrm{YY} / \mathrm{BY}$ & Kanun \\
\hline Slovenya & $\begin{array}{l}\text { GSYİH yüzdesi olarak borç } \\
\text { Borç tavanı }\end{array}$ & $\begin{array}{l}\text { Çok y1ll1 } \\
\text { Y1ll1k }\end{array}$ & $\begin{array}{l}\text { MY } \\
\text { YY }\end{array}$ & $\begin{array}{l}\text { Koalisyon } \\
\text { anlaş. } \\
\text { Kanun }\end{array}$ \\
\hline İspanya & $\begin{array}{l}\text { Bütçe dengesi Borç tavanı } \\
\text { Gelirin yüzdesi olarak borç }\end{array}$ & $\begin{array}{l}\text { Konjonktür } \\
\text { döneminde } \\
\text { Y1llık } \\
\text { Ylllık }\end{array}$ & $\begin{array}{l}\text { MY BY } \\
\text { YY }\end{array}$ & $\begin{array}{l}\text { Kanun } \\
\text { Kanun } \\
\text { Kanun }\end{array}$ \\
\hline İsveç & Ortalama bütçe açığı & $\begin{array}{l}\text { Konjonktür } \\
\text { döneminde }\end{array}$ & MY & $\begin{array}{l}\text { Politika } \\
\text { anlaşma }\end{array}$ \\
\hline İsviçre & Bütçe dengesi, borç freni & $\begin{array}{l}\text { Konjonktür } \\
\text { döneminde }\end{array}$ & MY & Anayasa \\
\hline İngiltere & $\begin{array}{l}\text { Altın kural } \\
\text { GSYİH'nın yüzdesi olarak borç }\end{array}$ & $\begin{array}{l}\text { Konjonktür } \\
\text { döneminde } \\
\text { Konjonktür } \\
\text { döneminde }\end{array}$ & $\begin{array}{l}\text { MY } \\
\text { MY }\end{array}$ & $\begin{array}{l}\text { Kanun } \\
\text { Kanun }\end{array}$ \\
\hline Avustralya & Bütçe dengesi, borç tavan1 & $\begin{array}{l}\text { Konjonktür } \\
\text { döneminde }\end{array}$ & MY & Kanun \\
\hline Brezilya & Gelirin yüzdesi olarak borç & Y1ll1k & MY ve YY & Kanun \\
\hline Kolombiya & Gelirin yüzdesi olarak borç & Y1ll1k & MY ve YY & Kanun \\
\hline Hindistan & Altın kural & Çok y1llı & MY & Kanun \\
\hline Y. Zelanda & Operasyonel denge & $\begin{array}{l}\text { Konjonktür } \\
\text { döneminde }\end{array}$ & MY & Kanun \\
\hline
\end{tabular}

MY:Merkezi Yönetim, YY:Yerel Yönetim, BY:Bölgesel Yönetim. 
Kaynak: (Symansky ve diğerleri, 2008, s. 9).

Tablo 1'de çeşitli ülkelerdeki mali kurallar; türlerine, planlama süresine, kapsamı ve yasal temeline göre yer almaktadır. Mali kuralların türlerinden borçlanma kuralı ve denk bütçe kuralının daha çok uygulandığı görülmektedir. Planlama süresine bakıldığında; yıllık, çok yıllı ve konjonktür dönemi olmak üzere üçlü bir ayrıma gidilmekle birlikte; denk bütçe kurallarının çok yıllı ve konjonktür döneminde uygulandığı dikkat çekmektedir. Kapsamları açısından mali kuralların daha çok merkezi yönetimlerde uygulandığı görülmektedir. Son olarak, yasal temelleri açısından değerlendirildiğinde ise, hemen hemen bütün ülkelerde uygulanan mali kuralların kanun ile yasalaştı̆̆ı göze çarpmaktadır.

\section{LI'TERATÜR ARAŞTIRMASI}

Mali kuralların altında yatan temel neden, mevcut veya gelecekteki hükümetlerin, çeşitli nedenlerle mali politika tedbirlerini uygulamaya istekli olmayacaklarıdır. Kuralların uygulanma gerekçelerinden bir diğeri ise, hükümetlerin "politik miyoplukları" ve "ortak havuz problemi"dir. Politik miyopluk, seçim beklentileri konusundaki endişelerden kaynaklanarak uzun vadeli gereksinimleri dikkate almamaktır. Bir diğer deyişle, hükümetler yeniden seçilme şansını artırabilmek için harcamaları artırabilmekte veya vergileri azaltabilmektedir. "Ortak havuz problemi" ise, özel çıkar gruplarının veya seçim bölgelerinin taleplerinin bütçe etkisini içselleştirememesinden ortaya çıkmaktadır (Cottarelli ve Kumar 2009, s. 15). Bunun dişında mali kuralların çeşitli nedenlerle kabul edildiği de görülmektedir. Bunlar; (a) savaş sonrası Japonya'da olduğu gibi makroekonomik istikrarın sağlanması; (b) bazı Kanada eyaletlerinde olduğu gibi hükümetin maliye politikasının güvenilirliğini artırmak ve bütçe açığını ortadan kaldırmak, (c) Yeni Zelanda'da olduğu gibi maliye politikasının uzun vadeli sürdürülebilirliğini sağlamak; (d) Avrupa Ekonomik ve Parasal Birliğinde olduğu gibi, bir federasyon veya uluslararası düzenlemede olumsuz dışsallıkları en aza indirmek (Kennedy ve diğerleri, 2001, s. 239).

Mali kuralların oluşturulma gerekçeleri genel olarak aşağıdaki gibi özetlenebilir (Kopits ve Symanski, 1998, s. 7);

- Maliye politikası kurallarının geleneksel gerekçesi olan makroekonomik istikrar açısından zorunluluk arz etmesi.

- Bir maliye politikası kuralının, diğer mali politikalara, özellikle de parasal araçların istikrara kavuşma hedefi doğrultusunda kullanılmasına yardımcı olabilmesi.

- Mali kuralların uzun vadeli mali sürdürülebilirliği ve mali disiplini sağlama veya sürdürme ihtiyacını karşılayabilmesi.

- Mali kuralların bir federasyon, konfederasyon ya da para birimi bölgesi içerisindeki olumsuz parçalanmaları önlemek amacıyla çeşitli hükümet düzeylerinde kullanılabilmesi.

- Bir mali kuralın, hükümet politikasının güvenilirliğini sağlamak için yararlı olabilmesi.

- Mali kurallara dayalı politikaların takdiri temelli bir yaklaşıma göre zaman tutarlığı olması.

- Mali kuralların mali disiplini teşvik ederek, kamu açıklarını ve borç seviyelerini azaltmaya yardimc1 olmasi.

Mali kuralların oluşturulma gerekçelerine yer verdikten sonra, mali kurallara ilişkin genel özelliklere de değinilmesi gerekmektedir. Bilindiği üzere mali kurallar; bütçe büyüklüğü üzerinde sayısal sınırlamalar yoluyla maliye politikasına uzun süreli kısıtlamalar getirmektedir. Bu ise, sınırları sıklıkla değiştirilemeyen bir maliye politikasının belirlendiği ve bütçe büyüklüğünün 
belirlenen sayısal bir hedefe göre sınırladığı anlamına gelmektedir. Dolayısıyla, mali kurallar genellikle bozulan teşvik yapılarını düzeltmeyi ve aşırı harcama yapmaya karşı sınırlandırmaları içermekte, mali sorumluluk ve borç sürdürülebilirliğini sağlamaktadır (Schaechter ve diğerleri, 2012, ss. 5-7). Mali kurallar, mali güvenilirliği ve disiplini destekleme amaçlı kurumsal mekanizmalardır. Mali kurallar farklı hedeflere hizmet edebiliyor olsa da öncelikle mali sürdürülebilirliği teşvik etmesi açısından önem taşımaktadır (Cottarelli ve Kumar 2009, ss. 4-5). Mali kurallar fonksiyonlarını yerine getirebilmesi için bazı genel özelliklere sahip olmalıdır. Bu özellikler (Buiter 2003, s. 84),

- Mali kurallar basit olmalıdır; uyumluluğu kolayca kanıtlanabilmelidir.

- Mali kurallar hükümetlerin borçlarını ödeme gücünü korumalıdır.

- Mali kurallar genel hükümetin mali açığı için uygulanmalıdır.

- Mali kurallar kamu kesiminin büyüklüğü konusunda tarafsız olmalıdır.

- Mali kurallar politika araçlarının konjonktürel davranışını teşvik etmemeli, otomatik mali dengeleyicilerin serbestçe çalışmasına izin vermelidir.

- Mali kurallar uzun vadede mantıklı olmalıdır.

- Mali kurallar ekonomik yapı ve başlangıç koşullarındaki farklılıklara izin vermelidir.

- Mali kurallar ulus devlet düzeyinde anlamlı olmalıdır.

- Mali kurallar güvenilir olmalıdır.

- Mali kurallar tarafsız ve tutarlı bir şekilde uygulanmalıdır.

Optimal mali kuralların sahip olması gereken temel özellikler aşağıda Şekil 1 yardımı ile gösterilmiştir,

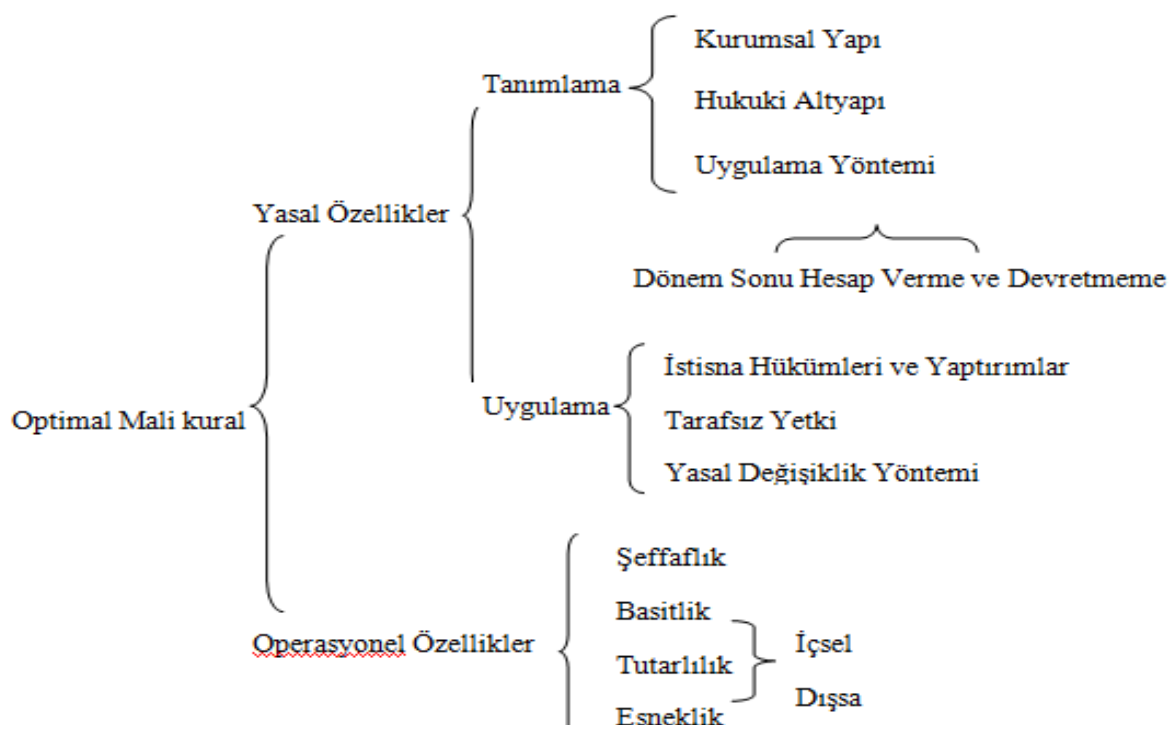

Şekil 1. Mali Kuralların Özellikleri

Kaynak: (Biraschi 2008, s. 11). 
Şekil 1'deki sınıflandırmada optimal bir mali kuralda bulunması gereken özellikler yasal ve operasyonel olmak üzere ikiye ayrılmaktadır. Mali kuralların düzgün ve sistemli bir şekilde işleyebilmesi açısından yasal özellikler çok önemlidir. Bu kuralların yasal altyapısındaki temel özelliklere bakıldığında, kurallara ilişkin istisnaların olmaması veya çok az olması gerekmektedir. Bunun dışında politikacıların taraflı davranışlarına karşı önlemler alınmalı ve ani şokların yaşanması halinde birtakım yasal değişiklik tedbirleri önceden belirlenmelidir. Kuralların operasyonel altyapısında ise bu kuralların sahip olması gereken temel özellikler belirtilmektedir. Bunlar, iyi tanımlanmış, şeffaf, uygun, tutarlı, basit, esnek, uygulanabilir ve etkin olan mali kurallardır. Bu özelliklere sahip olan mali kuralların başarı elde imkanı olacaktır.

Yukarıda maddeler halinde belirtildiği üzere mali kuralların sahip olması gereken özeliklerinin yanı sıra bu kuralların yürürlüğe konulması aşamasında esneklik, güvenilirlik ve şeffaflıkla ilgili bir takım sorunlar da ortaya çıkabilmektedir. Çünkü mali kurallar bazen aşırı derecede kısıtlayıcı olabilmekte ve gerektiğinde devletlerin konjonktürel maliye politikasını uygulaması konusunda yetkilerini sınırlandırmaktadır. Bu nedenle mali kurallara ilişkin mevzuat yazılırken bazı hususlara dikkat edilmesi gerekmektedir. Örneğin, mevzuatın işlevselliği açısından bazı esneklikler göz önünde bulundurularak yazılmalı ve bağlayıcılığı olmayan sınırlandırmalar konusunda esneklik olmayacak şekilde düzenlenmelidir. Buna ek olarak mali kurallar şeffaf olmalı, aşırı derecede karmaşık olmamalı ve mali göstergelerin izlenmesi ve tanımlanması açısından kolay olmalıdır. Ayrıca, güvenilirlik sağlama konusunda mali kuralların kalıcı olmasına da dikkat edilmelidir. Aksi takdirde uygulanan kuralların yasa veya anayasaya bağlı olarak uygulanıp uygulanmadığı konusunda şüphe uyandırabilmektedir (Kennedy ve diğerleri, 2001, s. 239). Bunların yanı sıra, kural temelli maliye politikası ile ilgili bazı endişeler de ortaya çıkmaktadır. Birincisi, disiplinli bir politika izlemek için yeterli siyasi bir taahhüdün olmadiğı veya yeterli önlemlerin alınmadığı hallerde benimsenen kuralların sürdürülmesi pek mümkün olmadığı için politika itibarının zayıflamasına neden olabilmektedir. İkincisi, mali kurallar takdir yetkisini bütçe açıkları ve borç tavanları konusunda kısıtladığı için konjonktürel durgunluğa götürebilmektedir. Üçüncüsü, mali kurallar genellikle mali uyumun bileşimi konusunda maliye politikasının kalitesini düşürebilmektedir. Bu ise, uzun vadeli büyüme beklentileri üzerinde olumsuz etki yaratan yüksek sosyal getirilere sahip kolay kesilebilen sermaye harcamalarına neden olabilmektedir. Dördüncüsü, kurallar bütçe dişı işlemleri teşvik ederek şeffaflığı azaltabilmektedir. Bu durumun özellikle büyük açıkların, borçların ve sürdürülebilirlik kaygılarının olduğu bir konjonktür ortamında daha fazla olması muhtemeldir (Cottarelli ve Kumar 2009, s. 15).

\section{MALI KURAL TÜRLERİ}

Mali kural uygulamaları ülkelerin kurumsal yapısı, ekonomik koşulları ve yönetim anlayışına bağlı olarak farklılık göstermekle birlikte, genel olarak mali kuralları türlerine göre beş kategoriye ayırmak mümkündür. Bu kategoride borçlanma kuralı, bütçe dengesi kuralı, yapısal bütçe dengesi kuralı, harcama kuralı, gelir kuralı yer almaktadır. Belirtilen kuralların uygulanmasında ise birçok ülkenin iki veya daha fazla mali kuralı birleştirdiği görülmektedir. Çünkü her mali kural çeşidi sürdürülebilirlik, ekonomik istikrar ve hükümet hedeflerinin boyutunu desteklemek için uygun değildir. Örneğin, bir harcama kuralı ile birleştirilen bir borç kuralı borç sürdürülebilirliği ile bağlantıyı sağlarken, aynı zamanda politika yapıcılara kısa ve orta vadeli operasyonel kararlar sunarak, hükümet boyutunu hedefleyebilir. Benzer şekilde, bir borç ve konjonktürel dönem için düzenlenmiş denk bütçe kuralı kombinasyonu yapılarak mali disiplin sağlanabilmektedir (Schaechter ve diğerleri, 2012, s. 9). 


\subsection{Denk Bütçe Kuralı}

Denk bütçe kuralı kamu gelirleri ve kamu harcamalarının birbirine denk olmasını öngörmekte ve yıllık denge, genel denge, cari denge ve operasyonel denge olmak üzere yıllık veya uzun vadeli dönemleri kapsamaktadır. Bütçe kuralları; kamu gelir ve giderlerinin denkliğini esas almakla birlikte, yalnızca yatırım harcamaları için borçlanabilmeye izin vererek cari dengeyi esas alan altın kuralları da kapsamaktadır. Bu sayede, kamu gelir ve giderlerinin denkliğinin yanı sıra cari harcama ve cari gelirlerin denkliği de sağlanmaktadır. Denk bütçe kuralları ile GSYİH, GSMH veya potansiyel hasıla gibi göstergeler dikkate alınarak yapılacak açıklar oranlar itibariyle sınırlandırılabilmektedir. Ayrıca toplam gelirler ile yapılan harcamalardan faiz ödemelerinin yok sayılması durumunda geriye kalan harcamalar arasındaki fark anlamına gelen faiz dışı fazla GSYİH, GSMH'ya oranlanarak sınırlandırılabilmektedir. Kısaca denk bütçe kuralı, bütçenin toplam gelir ve giderlerinin denk olmasını, borçlanmaya başvurulmamasını ve bütçe açığının GSYİH’ye oranının belirli bir oranla sınırlandırılmasını hedeflemektedir.

Bütçe sınırlamalarına ilişkin görüşler 1980'lerin ortalarından itibaren Amerika'da gündeme gelmiştir. Amerika Birleşik Devletleri’nde Federal Anayasaya denk bütçe ilkesinin getirilmesi gerektiği savunulmuş ve federal hükümet ile eyalet hükümetleri arasında bütçe dengesinin düzeltilmesine ilişkin bazı nedenler ortaya konmuştur. Eyalet hükümetlerinde borç senetleri çıkartıldığı için bütçe dengesizliği yaşanmış ve sadece Federal hükümet para basabildiği için, para basma yoluyla veya borç senedi çıkarma yoluyla federal bütçe dengeden uzaklaşmıştır. Dolayısıyla, para yaratma gücündeki temel farklılıktan dolayı, ABD'de eyaletlere nazaran federal düzeyde bütçe dengesi şartının getirilmesi söz konusu olmuştur (Buchanan ve Flowers, 1986, s. 5).

Denk bütçe kuralları, öncelikle borç oranını etkilemekte ve çoğunlukla politika yapıcıların kontrolü altındaki değişkenleri sınırlamaktadır. Bu nedenle, bu tür kurallar borçların sürdürülebilir olmasını sağlamaktadır. Denk bütçe kuralları genel denge, yapısal veya konjonktürel denge (ekonominin normal olarak kabul edilen üretim düzeyinde bulunmasiyla ortaya çıkacak olan bütçe açığı ya da fazlası) ve cari denge olarak spesifize edilmektedir. Genel denge kuralının ekonomik istikrar sağlama özelliği olmazken, diğerlerinin ekonomik şoklara karş1 cevap verebilme işlevi bulunmaktadır (Schaechter ve diğerleri, 2012, s. 7). Denk bütçe kuralları ile ilgili yapılan çalışmalarda; devlet bütçe açığının boyutu ve kalıcılığı ile devlet vergi ve harcama düzeyleri üzerindeki etkileri değerlendirilmiştir. Bunun sonucunda ise, mali kuralların mali politika çıktılarını etkilediği sonucuna varılmıştır. Örneğin, Bohn ve Inman (1995) mali kuralların etkisini tespit edebilmek amacıyla kırk yedi devletin yirmi yıllık süre zarfındaki incelemesini yapmışlar ve yılsonu bütçe açıklarını kısıtlayan denk bütçe kuralının devlet genel fon açığını azaltmada istatistiksel açıdan önemli bir etkiye sahip olduğunu bulmuşlardır (Poterba, 1996, s. 7). Alesina ve Bayoumi (1987) ise, ABD eyaletlerine yönelik yaptıkları araştırmada denk bütçe kurallarının mali disiplinin sağlanmasında etkili olduğu için düşük bütçe açıklarının elde edilmesini ve mali şoklara hızlı tepki verebilmesi açısından bütçe disiplininin korunması gerektiği sonucuna ulaşmışlardır. Bununla birlikte, politika yapıcıların bütçe kurallarının fayda ve maliyetlerini de göz önüne almaları gerektiğini belirtmişlerdir. Araştırmalarında "Hükümetler Arası İlişkiler Danışma Komisyonu" tarafından hesaplanan devlet bütçe kurallarının bir dizinini kullanarak bütçe kısıtlamalarını tespit etmişlerdir. Ayrıca, Alesina ve Bayoumi, bütçe kısıtlamalarının istikrar harcamalarını sınırlamakla birlikte, devlet çıktısını durgunluk döneminde artırabileceğini ve "hizmet kayırmacılığı" nedeniyle yapılan gereksiz harcamaları da sınırlandıracağını ileri sürmüştür (Krol, 1997, s. 303). Bütçe kuralları hakkındaki son araştırmalar ise, bütçeyi geliştirme ve yürürlüğe koyma ile ilgili çeşitli kuralların maliye 
politikasının tabiatını nasıl etkilediğini analiz etmektedir. Çünkü bütçe kuralları siyasi aktörlerin davranışlarının kontrol edilmesini sağlamakta ve bütçe görüşmelerine ilişkin takdir yetkilerini kısitlamaktadır (Poterba, 1996, s. 399).

\subsection{Gelir ve Harcama Kuralı}

Harcama kuralları mutlak anlamda toplam, birincil veya cari harcamalara, gerçek büyüme hızlarına (veya gerçek potansiyel büyüme oranına) veya GSYİH'ya oran olarak kalıcı sınırlar getirmektedir. Bu kurallar genellikle şeffaftır (doğrudan bütçeyi sınırlandırır), makroekonomik istikrarı ve mali disiplini sağlamaktadır. Harcama kuralları doğrudan borçlanma ve sürdürülebilirlik hedefiyle (gelir tarafını sınırlamadıkları için) bağlantılı olmamasına rağmen, bir borç freni eşliğinde, mali sürdürülebilirlikle uyumlu bir mali konsolidasyonu tetikleyebilir. Konuyla ilgili olarak Cordes ve diğerleri (2015), harcama kurallarının diğer mali kurallara göre daha iyi operasyonel rehberlik ve şeffaflık sağlama hedeflerini karşıladığını tespit etmişlerdir (Andrle ve diğerleri, 2015, ss. 13-16).

Harcama kuralları, vergi gelirlerinde konjonktürel veya ihtiyari indirimlerin yapılmasını gerektirmediği için, olumsuz şoklar yaşandığı zaman maliye politikasının ekonomik istikrar işlevini kısıtlamamaktadır. Harcama kuralları ihtiyari mali teşviklere uygun olmadığı için, belirlenen harcama tavanları hükümetin kullandığı kamu kaynaklarının miktarını doğrudan tanımlamakta ve bu sayede izlenmesini kolaylaştırmaktadır (Schaechter ve diğerleri, 2012, s. 9). Bir harcama kuralı, ekonomiyi güçlendirme ve bütçeyi iyileştirme gibi durumlarda daha fazla avantaja sahiptir. Çünkü harcama temelli bir mali kural ekonominin olumsuz olmasına bakmaksızın, bütçedeki otomatik dengeleyicilerin sürekli çalışmasına izin vermektedir. Örneğin, harcama kuralları ile doğal afetler ve bu koşullar altında öngörülemeyen ihtiyaçların gerektirdiği bir defalık harcamaların yapılmasına izin verilebilmektedir (Anderson ve Minarik 2006, s. 184). $\mathrm{Bu}$ tür kurallar mali disiplini doğrudan ilgilendirmemekte, hükümetin boyutunu sinırlamay1 amaçlamaktadır. Harcama kurallarının varlığı, daha yüksek bir faiz dışı denge ve daha güçlü bir mali performans ile ilişkilendirilmektedir. Harcama kurallarına uyum; özellikle harcama kuralı doğrudan hükümetin kontrolü altındaysa ve kural yasada ya da koalisyon sözleşmesinde yer alıyorsa, bütçe dengesi kurallarından daha fazla olmaktadır (Cordes ve diğerleri, 2015, s. 17).

Harcama kurallarının bazı sınırlamaları olmasına rağmen, diğer kural türlerine göre daha cazip hale getiren ve bütçe disiplini ile makroekonomik istikrar hedefleri arasında uygun dengeyi gösteren bazı özellikler sunmaktadır (Casals, 2012, s. 3);

- Hükümet tarafından doğrudan kontrol edilen bütçenin bir bölümünü hedef almaktadır. Böylece belirlenmiş mali hedefin ve daha yüksek bir hesap verebilirlik derecesinin sağlanması konusundaki belirsizlik azaltılmaktadır. Buna ek olarak, hükümet görünür ve operasyonel olarak hedeflenen bir harcamayı, diğer bir deyişle harcama hedefini kamuya açıklamaktadır.

- Hedef formülasyonunun ve takibinin diğer mali kural türlerinden daha basit olması ve kamuoyuna ve seçilmiş temsilcilerle aktarılması daha kolay olması bakımından şeffaftır.

- Harcama kuralları otomatik dengeleyicilerin özellikle gelir tarafında çalışmasını engellememekte ve refah zamanlarında harcamaların azalmasına yardımcı olabilmektedir.

Gelir kuralları ise, gelirler üzerindeki tavanları veya tabanı belirlemekte ve gelir tahsilatını artırmayı ve aşırı bir vergi yükünü önlemeyi amaçlamaktadır. Bu kuralların çoğu kamu borcunun kontrolü ile doğrudan bağlantılı olmamakta ve bu kurallar harcamaları sınırlamamaktadır. Bununla birlikte, harcama kuralları gibi hükümetin boyutunu da doğrudan hedef alabilmektedir (Schaechter ve diğerleri, 2012, s. 9). Gelir kurallarının etkinliği büyük ölçüde hedef tanımlarına 
bağlı olmaktadır. Ayrıca, tek başlarına mali disiplini sağlayamamaktadırlar. Gelir kurallarının tasarımında en ilginç olan şey; konjonktürel olmayan politikaların uygulanmasını önlemeyi amaçlamasıdır. Bunun başarılması ise, mali otoritelerin bütçe kanununda harcamaların refah zamanlarında sınırlanmasına izin verebilecek, beklenenden yüksek gelir tahsisinin önceden belirtilmesini zorunlu tutmasına bağlıdır (Casals, 2012, s. 18). Gelire yönelik kurallar, kamu gelirlerinin belirli bir tavan ile sınırlandırılmasını öngördüğü için bu sınırlama çoğunlukla birincil kamu geliri olan vergilerde ortaya çıkmaktadır. Yani, vergi yükü belirli bir seviyede tutularak hem devletin keyfiliği engellenmekte hem de devletin büyüklüğü sınırlandırılmaktadır.

Anayasal İktisat'ın kurucusu olan ve devletin güç ve yetkilerinin sınırlandırılması gerektiğini savunan James M. Buchanan, vergi oranları ile vergi konusunun anayasal çerçevede sınırlandırılması gerektiği kanaatindedir. Vergi oranlarının maksimum sınırının belirlenmesi gerektiği ile artan, azalan ve sabit oranlı vergilerin hangi vergi konularına uygulanacağının açık bir şekilde anayasalarda belirtilmesi düşüncesindedir. Devletin daha da büyüyüp genişlemesini engellemek amacıyla önerdiği bir diğer vergi reformu mali federalizmin getirilmesidir. Mali federalizm ile merkezi idarenin vergileme gücü mahalli idarelerle paylaştırılarak sınırlandırma getirilmiş olacaktır. Buchanan, devletin kamu harcamalarının gerçek maliyetlerini bireylerden gizlediğini ve kamusal gelirlerini artırmaya çalıştığını savunmaktadır. Başka bir deyişle, politik kaygılar ile oy maksimizasyonu sağlamak amacıyla bireylerden vergi almadan, sadece kamu harcamaları yapması sonucunda "vergilemeden harcama yapma" mekanizmas1 ortaya çıkmaktadır. Vergi almadan devamlı harcama yapılması sonucunda ise, bu harcamaları karş1layacak gerekli finansman ihtiyacı borçlanarak veya emisyon yoluyla karş1lanmaya çalışılacaktır. Bu şekilde devam eden bir sistemin sonucunda ise bütçe açıklarında görülen artışlar devam edecektir.

\subsection{Borçlanma Kuralı}

Borçlanma kuralları, kamu borcu için GSYİH'nın yüzdesi olarak açık bir sınır veya hedef belirlemektedir. Borçlanma kuralı bir borç hedefine yakınsamada en etkili olanıdır ve herkes tarafından anlaşılması nispeten kolaydır (Schaechter ve diğerleri, 2012, s. 8). Borçlanma kuralları, devlet iç borçlanmasına ilişkin sınırları veya merkez bankasından devlet borçlanmasına ilişkin sınırları belirlemektedir. Başka bir deyişle, borçlanmaya getirilen sınırlamalar finansmanın kaynağına veya borçlanan hükümetin ulusal veya yerel yönetim olmasına göre belirlenmektedir (Kopits ve Symansky, 1998, s. 2). Borçlanmaya ilişkin kurallar incelendiğinde, yurtiçi kaynaklardan borçlanmaya yönelik birtakım sınırlamaların getirilmesi veya toplam borçlanmaya nominal limitler uygulanması ya da toplam borç miktarının GSMH'ya oranlanması suretiyle de borçlanma kurallarının oluşturulduğu görülmektedir. Borçlanmaya ilişkin olarak belirtilen oranlar ile sınırlandırmanın dışında bir de borç stokuna yönelik kurallar getirilmektedir. Borç stoku da borçlanmaya benzer şekilde nominal veya GSMH'ya oranlanması suretiyle yapılmaktadır. Örneğin, Polonya uygulamış olduğu Maastricht kriteri gereği kamu borçlarının GSYİH'ya oranının \% 60'ı aşmamasına dikkat etmektedir. İngiltere, altın kural sınırlaması gereği kamu borçlanmasını sadece yatırım harcamaları için yapabilmekte ve borç stokunun GSYİH'ya oranının da \%40’ı aşmaması gerekmektedir. Brezilya ise, uygulamış olduğu Mali Sorumluluk Yasası gereğince, yerel ve merkezi hükümetlerin borçları ile personel ödemeleri üzerine üst sınırlar getirmiştir. Avro bölgesinde bulunan AB üyesi ülkeler ise, merkezi hükümet borçlarının GSYİH’nın \%60'ını aşmaması şeklinde borç stoğuna ilişkin sınırlama getirmiştir.

Buraya kadar aktarılan mali kurallar ve bu kuralların sağladıkları faydalar ile eksikliklerine Tablo 2'de yer verilmektedir. 
Tablo 2. Mali Kural Türlerinin Özellikleri

\begin{tabular}{|c|c|c|}
\hline Kural Tipi & Artıları & Eksileri \\
\hline $\begin{array}{l}\text { Borçlanma } \\
\text { Kuralı }\end{array}$ & $\begin{array}{l}\text { Borç sürdürülebilirliği } \\
\text { ile doğrudan } \\
\text { bağlantılıdır. } \\
\text { - Herkes tarafından } \\
\text { anlaşılması ve izlenmesi } \\
\text { kolaydır. }\end{array}$ & 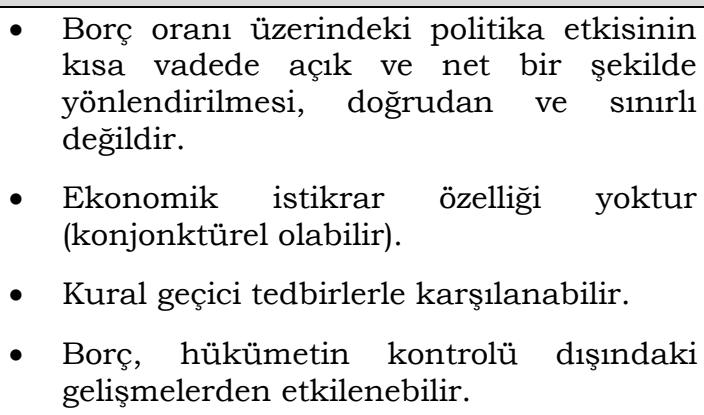 \\
\hline $\begin{array}{ll}\text { Denk } & \text { Bütçe } \\
\text { Kuralı } & \end{array}$ & $\begin{array}{l}\text { - } \begin{array}{l}\text { SSeffaf operasyonel } \\
\text { rehberlik sağlar. }\end{array} \\
\text { - } \quad \begin{array}{l}\text { Borç sürdürülebilirliği } \\
\text { ile yakın bağlantılıdır. }\end{array} \\
\text { - } \quad \text { Herkes tarafından } \\
\text { anlaşılması ve izlenmesi } \\
\text { kolaydır. }\end{array}$ & $\begin{array}{ll}\text { - } & \text { Ekonomik istikrar özelliği yoktur } \\
\text { - Hükümet dengesi, hükümet kontrolü } \\
\text { dişındaki gelişmelerden etkilenebilir } \\
\text { (büyük ekonomik krizler) }\end{array}$ \\
\hline $\begin{array}{l}\text { Yap1sal Denk } \\
\text { Bütçe Kuralı }\end{array}$ & $\begin{array}{ll}\text { - } & \text { Nispeten şeffaf } \\
\text { operasyonel rehberlik } \\
\text { sağlar. }\end{array}$ & $\begin{array}{l}\text { - Özellikle yapısal değişiklikler geçiren } \\
\text { ülkeler için konjonktürel düzenlemeler } \\
\text { karmaşıktır. } \\
\text { - İhtiyari kullanımını önlemek için bir } \\
\text { defaya mahsus ve geçici faktörlerin } \\
\text { önceden tanımlanması gerekmektedir. } \\
\text { - Bildirimleri ve izlenmesi daha zor } \\
\text { olmaktadır. }\end{array}$ \\
\hline $\begin{array}{l}\text { Harcama } \\
\text { Kuralı }\end{array}$ & 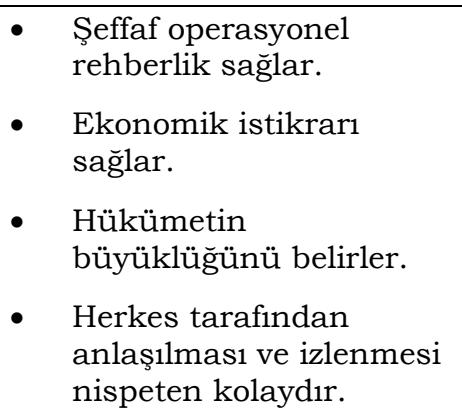 & 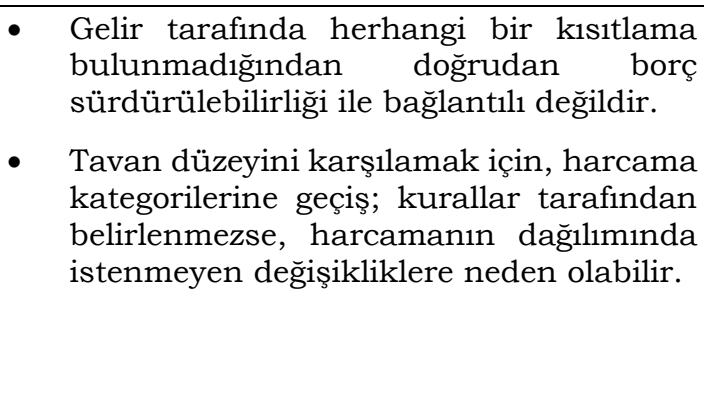 \\
\hline Gelir Kuralı & $\begin{array}{ll}\text { - } & \text { Hükümetin } \\
\text { büyüklüğünü belirler. } \\
\text { • } & \text { Gelir politikası ve } \\
& \text { yönetimini iyileştirebilir. } \\
\text { - } & \text { Konjonktürel } \\
& \text { harcamaları önleyebilir. }\end{array}$ & $\begin{array}{l}\text { - Harcama tarafinda herhangi bir kısıtlama } \\
\text { bulunmadığından doğrudan borç } \\
\text { sürdürülebilirliği ile bağlantılı değildir. } \\
\text { - Ekonomik istikrar özelliği yoktur. }\end{array}$ \\
\hline
\end{tabular}

Kaynak: (Schaechter ve diğerleri, 2012, s. 8). 


\section{MALI KURALLARA İLISŞKIN AMPİIIK ARAŞTIRMALAR VE SONUÇLARI}

Mali kurallarla ilgili son zamanlarda yapılan ampirik çalışmalar çeşitli konulara odaklanmıştır. Bu çalışmalarda; (a) Mali kuralların etkili olup olmadığı; (b) Mali kuralların özellikleri ile etkinliği arasında nasıl bir ilişki olduğu; (c) Mali kuralların hükümetlerin maliye politikası uygulamalarına yönelik yetkilerini sınırlayıp sınırlamadığı ve (d) Mali kurumların ve düzenlemelerin mali kurallar üzerindeki etkisi vb. daha pek çok konu ele alınmaktadır.

a) Mali kuralların etkili olup olmadığına ilişkin yapılan birtakım ampirik araştırmalar ve elde edilen bulgular şöyledir;

Kneebone ve McKenzie (1997), Kanada'daki Alberta hükümetindeki harcamaların ve gelirlerin beklenmedik şoklara karşı etkilerini incelemişlerdir. $\mathrm{Bu}$ araştırmada, gelirde yaşanan beklenmedik kayıpların mevcut bütçe durumunu etkilemezken, gelirde yaşanan beklenmedik artışların mevcut gelir planlarına dahil edildiğine yönelik asimetrik sonuçlar bulmuşlardır. Bu asimetrik durumun nedenini ise, Alberta hükümetinin mevzuatına bağlamışlardır. Onlara göre, borçların azaltılması için kullanılacak olan gelirler yetersiz kalmış ve daha fazla gelir elde edilmesi gerekmiştir. Ancak, Alberta'nın o zamanki mevzuatında hükümetin kurumlar vergisi ile diğer vergi gelirlerinin tamamını bütçelemesi yasaklanmıştır. Bu durum ise böyle bir asimetrik sonuca neden olmuştur. Eichengreen ve Bayoumi (1994), mali kuralların devletin genel tahvil getirileri üzerindeki etkisini araştırmışlardır. Bulgularına göre, bir ülkede borç-gayrisafi milli hasıla oranı, vergi oranları ve devlet işsizlik ortalama seviyeleri için daha sıkı vergi ve harcama limitlerinden birinin yürürlüğe girmesi durumunda faiz maliyetleri yaklaşık elli puan azalacaktır. Bu nedenle Eichengreen ve Bayoumi, vergi ve harcama limitinin gelecekteki borç artışı ihtimalini ve dolayısıyla temerrüde düşme ihtimalini azalttığını savunmuşlardır. Goldstein ve Woglom (1992), borçlanma konusunda sınırlamalar getiren devletlerin borçlanma maliyetini düşürdüğünü bulmuşlardır. Mattina ve Delorme (1996) ise mali disiplini sağlayabilen mali kurallar dışında başka bir faktörün varlığını vurgulamışlardır. Araştırmaları, piyasa mekanizmaları tarafından uygulanan disiplinin; mali açıdan politikaları teşvik etmede etkili olabileceğini göstermektedir (Kennedy ve diğerleri, 2001, ss. 255-256).

Alesina ve Bayoumi ise, ABD'de denk bütçe kurallarının mali disiplinin uygulanmasında etkili olduğunu ve bütçe açıklarına sınırlamalar getiren sıkı mali kontrollerin; ortalama açıkları azalttığını tespit etmişlerdir. Onlara göre, mali kısıtlamalar sadece "iyi" anti konjonktürel politikaları engellememekte, aynı zamanda istikrarı bozucu bir etkiye sahip olabilecek siyasi politikaları da sınırlandırmaktadır (Alesina ve Bayoumi, 1996, ss. 8-9).

Poterba ve Rueben, vergi ve harcama limitlerinin borçlanma maliyetleri açısından farklı sonuçlar doğurduğunu bulmuşlardır. Onlar, vergi sınırlamalarına yönelik mevzuata sahip devletlerin benzer kanunlara sahip olmayan devletlerden daha yüksek borçlanma maliyetlerine maruz kaldıklarını tespit etmişlerdir (Poterba ve Rueben, 1999, s. 24).

Bohn ve Inman ise, mali kuralların etkilerini tespit etmeye çalışmışlar ve denk bütçe kurallarının yılsonundaki bütçe açıklarını sınırlandırmasının; devletlerin genel fon açığını oldukça azalttığını belirlemişlerdir (Bohn ve Inman, 1996, s. 13).

b) Mali kuralların özellikleri ile etkinliği arasında nasıl bir ilişki olduğuna ilişkin yapılan ampirik araştırmalar ve elde edilen bulgular şöyledir, 
Mali kuralların özellikleri ve etkinliğine ilişkin birtakım ampirik çalışmalar da yapılmıştır. Mali kuralların etkinliği kuralın tasarımına ve kuralın ulusal, siyasi veya kurumsal yapıya uyup uymamasına bağlı olabilmektedir. Bunun dışında, kuralların etkinliğini belirlemede önemli olan diğer faktörler hesap verebilirlik, izleme ve uygulama mekanizmalarıdır. Avrupa ülkelerinde genel hükümet düzeyinde mali kurallarla ilgili son zamanlardaki ampirik çalışmalar ile mali kuralların etkinliğinin ilgili ülkenin kurumsal ve politik geçmişine bağlı olduğu tespit edilmiştir (Foremny, 2014, s. 89). Dolayısıyla, yapılan çalışmalarda mali kuralların özellikleri ile etkinliği arasındaki ilişki değerlendirilirken, belirlenen kuralların sıkı veya esnek olup olmaması, uygulanma alanı veya süresi gibi birtakım kriterler göz önünde bulundurulmaktadır.

Stansel, etkili bir şekilde tasarlanmış vergi ve harcamaya yönelik kuralların vergi ve harcamaların büyümesini sınırlandırabildiğini söylemektedir. Araştırmasına göre, ABD’de vergi ve harcamaya yönelik kuralların yürürlüğe girmeden beş yıl öncesine bakıldığında; kişi başına düşen devlet harcamalarının büyüme oranı; Amerika Birleşik Devletleri ortalamasının yüzde 0,8'ini oluşturmaktayd1. Vergi ve harcamaya yönelik kuralların yürürlüğe girmesini takiben beş yıl içinde bu oranın ABD ortalamasının 2,9 puan altına düştüğünü tespit etmiştir (Stansel, 1994, s. 2).

Bohn ve Inman, araştırmasında farklı kural türlerinin etkinliğini keşfetmek amacıyla 1970-1991 yılları arasında ABD eyaletlerini de incelemişlerdir. Denk bütçe kurallarının daha sıkı olması ile daha yüksek devlet fazlası arasında ilişki tespit etmişlerdir. Yaptıkları analiz sonucunda, en etkin kuralların bütçe öncesi şartlar yerine, yılsonu dengesi için geçerli olan anayasal gereklilikler olduğunu söylemişlerdir (Bohn ve Inman, 1996, s. 20).

Von Hagen (1991) yaptığı bir çalışmasında, borç limitleri olan ve olmayan devletlerdeki mali performans göstergelerini ve denk bütçe kurallarına göre değişiklik gösteren devletleri karşılaştırarak, ABD eyaletlerindeki borç limitleri ve denk bütçe kurallarının etkinliğini incelemektedir. Onun analizi, borç sınırlarının veya katı denk bütçe kurallarının varlığının, kişi başına düşen devlet borcunun dağılımını ve borç-gelir oranını etkilediğini göstermektedir. Borç limitleri olan veya sıkı denk bütçe kurallarına sahip olan eyalet gruplarında garantisiz borçların garantili borçlardan daha yüksek oranlara sahip olduğunu bulmuştur. Dolayısıyla, devlet borç limitlerinin sadece garantili borçları kısıtladığı ve bütçe kurallarının sadece bütçe veya genel hesap faaliyetlerini hedeflediğini göz önünde bulundurarak, devletlerin muhasebe önlemleri ile mali kuralların etkisini önlemeye çalıştıklarını saptamıştır (Kennedy ve diğerleri, 2001, ss. 256257).

Levinson 1969-1995 yılları arasında yaptığı araştırmada bazı ABD eyaletlerinde (50 eyalet) uygulanan katı denk bütçe kurallarının, bu eyaletlerde konjonktürel dalgalanmaları daha da artırdığına dair kanıtlar bulmuştur. Levinson bu araştırmasında ayrıca, sıkı maliye politikası uygulayan büyük devletlerdeki konjonktürel dalgalanmaların, maliye politikasını daha az uygulayan küçük devletlerdeki konjonktürel dalgalanmalardan daha fazla olduğu sonucuna da ulaşmıştır (Levinson, 1998, s. 730).

c) Mali kuralların hükümetlerin maliye politikası uygulamalarına yönelik yetkilerini sınırlayıp sınırlamadığına ilişkin yapılan birtakım ampirik araştırmalar ve elde edilen bulgular şöyledir;

Mali kurallarla ilgili araştırmalar genel anlamıyla hükümetin ekonomik dalgalanmaları düzenlemek amacıyla maliye politikasını kullanma kabiliyetini ve hangi araçlar konusunda sınırlandırılmaların yapılması gerektiğine yöneliktir. Bayoumi ve Eichengreen mali kurallar ile ilgili yaptığı araştırmada, Amerika Birleşik Devletleri için devlet bütçelerinin 1970'ler ve 1980'lerde makroekonomik istikrarda önemli bir rol oynadığını tespit etmişlerdir. Mali yapının 
Amerika Birleşik Devletleri'ndeki eyalet hükümetleri tarafından mali istikrara kavuşturulmasında önemli bir role sahip olduğunu işaret etmişlerdir. Bunun dışında, devlet bütçelerinin konjonktürel değişime karşı cevap verip verememesi noktasında bütçelerin mali sınırlamalardan önemli ölçüde etkilendiğini vurgulamışlardır (Bayoumi ve Eichengreen, 1995, s. 46).

Poterba bütçe dengesine yönelik olarak ABD’yi devlet düzeyinde incelemiş ve bütçe kurallarında meydana gelen değişikliklerin maliye politikası sonuçlarını etkileyebileceğini göstermiştir. Çalışmasında, denk bütçe kurallarının devlet bütçesi açıklarının büyüklüğü ile vergi ve harcama seviyeleri üzerindeki etkilerini değerlendirmiştir. Bütçe kurallarının özellikle devlet borçlanmasına ilişkin sınırlandırmalar ile birleştirildiğinde devlet açığını azalttığı, harcama ve borçlanma seviyelerini de etkilediği sonucuna ulaşmıştır. Ayrıca Poterba, vergi sınırlandırmaları ile ilgili yasaların bütçe açığının azaltılmasına yönelik etkisini de değerlendirmiştir. Buna göre, vergi sınırlamaları ile ilgili yasalara sahip olan devletlerin, herhangi bir yasal sınırlamaya tabi olmayan devletlere göre, beklenmedik açıklar karşısında daha küçük vergi artışları gerçekleştirdiğini tespit etmiştir (Poterba, 1996, ss. 395-398).

Fatas ve Mihov (2006), mali kuralların ihtiyari maliye politikasının daha az kullanımı ile ilişkili olduğunu ve maliye politikasının konjonktür dalgalanma hareketlerine karşı duyarlılı̆g azalttığ sonucuna ulaşmışlardır (Kukk ve Staehr, 2015, s. 78).

d) Mali kurumların ve düzenlemelerin mali kurallar üzerindeki etkisine ilişkin yapılan birtakım ampirik araştırmalar ve elde edilen bulgular şöyledir;

Hallerberg ve diğerleri (2007), AB ülkelerinde mali kuralların bütçe sürecinin üzerindeki etkisini incelemek amacıyla Avrupa'da bütçe kurumları üzerine bir çalışma yapmışlardır. Yaptıkları çalışmada mali kuralların, hükümetin ideolojik dağılımına bağlı olarak Avrupa ülkelerindeki etkisinin nasıl olduğunu araştırmışlardır. 1985-2004 dönemine ait ampirik kanıtlar, bütçeleme sürecinin merkezileştirilmesinin kamu borcunu kısıtladığını göstermiştir. Şöyle ki, tarafların uyumlu olduğu ve aralarındaki siyasi rekabetin düşük olduğu tek parti hükümetleri veya koalisyon hükümetleri olan ülkelerde, bu, maliye bakanına karar verme yetkisiyle sağlanmaktadır. Dolayısıyla, mali kurallar ideolojik olarak dağınık koalisyonları olan ve tarafların düzenli olarak birbirleriyle rekabet ettiği ülkelerde mali disiplini artırmaktadır (Hallerberg ve diğerleri, 2007, s. 338).

Poterba (1995) yaptığı bir çalışmasında, denk bütçe kurallarının siyasi tercihlerin kontrolünde etkisinin olduğu sonucuna varmıştır. Çalışmada, denk bütçe kuralları ile maliye politikası arasında korelasyon olduğu iddia edilmiştir. Poterba, politika değerlendirmesi için kritik olan sorunun, bu korelasyonların nasıl yorumlanacağı olduğunu belirtmiştir. Ona göre, mali disiplin, mali kurumlar ve mali kısıtlama için ihmal edilen üçüncü değişken olan seçmenler arasında bir ilişki olması mümkündür. Çünkü Poterba'ya göre, yargı alanındaki seçmenler, mevcut devlet programlarını desteklemek veya mevcut devlet programlarındaki ödeme yükünü geleceğe aktarabilmek için borçlanmaya daha az eğilimli olabilmektedir (Poterba, 1995, s. 335).

Wyplosz (2005) ve De Haan ve diğerleri (2004) ise, mali kuralların etkinliğinin kurumsal düzenlemelere bağlı olduğunu bulmuştur. Wyplosz (2005), yaptığ1 çalışmasında para politikası için benimsenen kurumların maliye politikasına da uygulanabileceğini savunmuştur. Bunu gerçekleştirecek olan kurumun ise oluşturulacak bağımsız Mali Politika Komiteleri olacağını ve bu kurumun Para Politikası Komiteleri ile aynı rolü oynayarak açıklara ve borcun gelişimine karar vereceğini, bu sayede bütçe açı̆̆ı ve borçlanmanın sürdürülebilirliğinin sağlanacağı sonucuna varmıştır (Wyplosz, 2005, s. 77). 
De Haan ve diğerleri ise, İstikrar ve Büyüme Paktı'nın mali kuralları uygularken başarı sağlayabilmesi için nasıl bir yol izlemesi gerektiğini araştırmışlardır. Çalışmalarında, İstikrar ve Büyüme Paktı'nın uygulayıcı mekanizmasının çok zayıf olduğu ve büyük ülkelerin mevcut maliye politikası kurallarına uyma olasılıklarının daha düşük olduğunu iddia etmişlerdir. Analizlerinde ayrıca, büyük üye devletlerin yürürlükte olan kurallar tarafından kısıtlanma olasılığının düşük olduğunu da göstermişlerdir. Dolayısıyla İstikrar ve Büyüme Paktı'nın otomatik yaptırım içermemesi nedeniyle yaptırımların uygulanacağının garantisi olmadığını ve esnek kurallar yerine daha katı kuralların getirilmesi gerektiği sonucuna varmışlardır (De Haan ve diğerleri, 2004, s. 235).

Bohn ve Inman (1996), mali kuralların yalnızca devlet anayasasında ve bağımsız bir yüksek mahkeme tarafından güvence altına alındığında etkili olduğunu da bulmuşlardır. Buti ve Giudice (2002), Maastricht Antlaşması'nın borç ve açık kriterlerinin etkisini değerlendirmişler ve kriterlerin AB'ye başvuran ülkelerin açıklarının azaltılması anlamında etkili olduğunu bulmuşlardır (Kukk ve Staehr, 2015, ss. 78-79).

\section{SONUÇ}

Maliye politikalarına yönelik uygulamalar özellikle 1970’li yıllara kadar aşırı devlet müdahalesi anlayışına bağlı olarak ihtiyari bir şekilde yönlendirilmiştir. 1970’li y1llara kadar uygulanan genişletici ve ihtiyari maliye politikaları ülkeleri borç batağına sokarak durgunluğa sürüklemiş, yüksek enflasyon ve işsizliğin bir arada yaşanmasına neden olarak ekonomik büyümenin olumsuz etkilenmesine neden olmuştur. Buna bağl1 olarak 1970 ve 1980'li y1llarda ihtiyari maliye politikaları terkedilerek yerine kurallara dayalı maliye politikaları getirilmiştir. Bu bağlamda; gelir, harcama, borçlanma ve bütçeye yönelik orta ve uzun dönemde izlenecek politikaların kurallara bağlanması ve belirlenen sınırlandırmalar doğrultusunda uygulanması kurala dayalı maliye politikası olarak ifade edilmektedir.

Mali kurallar, ülkelerin yönetim tarzlarına ve sahip oldukları ekonomik-politik koşullara göre değişiklik göstermektedir ve buna bağlı olarak da farklı kısıtlamalar şeklinde ortaya çıkmaktadır. Dolayısıyla, mali kuralların oluşturulma nedenleri farklı amaçlara hizmet etmektedir. Örneğin, vergi ve harcama kısıtlamaları devletin büyüklüğünü (devlet müdahalesini) belirlerken, bütçe kısıtlamaları genellikle mali disiplin ve mali sürdürülebilirlik amaçları için getirilmiştir. Kısaca, ekonomik göstergeler üzerine getirilen mali sınırlandırmalar yani, mali kurallar ile öncelikli olarak amaçlanan; maliye politikası araçlarının siyasal otoritelerin kişisel çıkarları doğrultusunda kullanılmasını engellemek ve uzun dönemde mali disiplini tesis ederek ekonomik istikrarın sağlanmasıdır.

Küresel dünyada hızla önem kazanan mali kurallar; günümüzde de maliye politikalarının önemli bir bileşeni haline gelmiştir. Bu çalışma kapsamında konuyla ilgili yapılan ampirik araştırmalar incelenmiş ve sonuç olarak mali kuralların gerekli olup olmadığından ziyade, bu kuralların nasıl düzenlenmesi gerektiği hususunun önem arz ettiği kanaatine ulaşılmıştır. Bu bağlamda, mali kuralların mali disiplin ve mali sürdürülebilirlik üzerinde olumlu etkisini gösterebilmesi için, yasal bir dayanağı olması, basit ve uygulanabilir olması, istikrarlı ve uzun vadeli olması, kamu kesiminin optimal büyüklüğünü dikkate alarak belirlenmesi vb. birtakım özelliklere sahip olması gerekmektedir. Sonuç olarak, bu özellikler doğrultusunda hazırlanacak ve uygulanacak olan kurala dayalı maliye politikaları; ülke ekonomilerinin uzun dönemde şeffaf, öngörülebilir ve istikrarlı bir yapısal dengede yol almasını sağlayacaktır. 


\section{KAYNAKÇA}

Alesina, A. ve Bayoumi, T. (1996). The costs and benefits of fiscal rules: Evidence from US states (No. w5614). National Bureau of Economic Research, 1-16.

Anderson, B. ve Minarik, J. (2007). Design choices for fiscal policy rules. OECD Journal On Budgetıng, 5(4), 159-209.

Andrle, M., Bluedorn, M. J. C., Eyraud, L., Kinda, M. T., Brooks, P. K., Schwartz, M. G. ve Weber, A. (2015). Reforming fiscal governance in the European Union (No. 15-19). International Monetary Fund.

Bayoumi, T. ve Eichengreen, B. (1995). Restraining yourself: the implications of fiscal rules for economic stabilization. Staff Papers, 42(1), 32-48.

Bergman, U. M., Hutchison, M. M. ve Jensen, S. E. H. (2016). Promoting sustainable public finances in the European Union: The role of fiscal rules and government efficiency. European Journal of Political Economy, 44, 1-19.

Biraschi, P. (2008). Searching for the optimal EMU fiscal rule: An ex-post analysis of the SGP reform proposals. Ministry of Economy and Finance Department of the Treasury Working Paper, (7).

Bohn, H. ve Inman, R. P. (1996). Balanced-budget rules and public deficits: Evidence from the US states. Carnegie-Rochester Conference Series on Public Policy, 45,13-76.

Buchanan, J. ve Flowers, M. (1986). The Public Finance (Ö. Ferhat B. Çev.). Mali sürece ilişkin kuralların iyileştirilmesi amacıyla vergi ve harcama yetkilerinin çerçevesinin belirlenmesi. Erişim adresi: http://www.canaktan.org/ekonomi/anayasal_iktisat/diger_yazilar/ozgenmali-surece-iliskin.pdf.

Buiter, W. H. (2003). Ten commandments for a fiscal rule in the EMU. Oxford Review of Economic Policy, 19(1), 84-99.

Casals, J. A. (2012). National expenditure rules-why, how and when. Directorate General Economic and Financial Affairs European Commission, 473, 1-64.

Cordes, T., Kinda, M. T., Muthoora, M. P. S. ve Weber, A. (2015). Expenditure rules: Effective tools for sound fiscal policy?. International Monetary Fund, 15-29.

Cottarelli, C. ve Kumar, M. (2009). Fiscal rules-anchoring expectations for sustainable public finances. International Monetary Fund, 1-72.

De Haan, J. , Berger, H. ve Jansen, D. J. (2004). 'Why has the stability and growth pact failed?. International Finance, 7(2), 235-260.

Hallerberg, M., Strauch, R. ve Von Hagen, J. (2007). The design of fiscal rules and forms of governance in European Union countries. European Journal of Political Economy, 23(2), 338-359.

Foremny, D. (2014). Sub-national deficits in European countries: the impact of fiscal rules and tax autonomy. European. Journal of Political Economy, 34, 86-110.

Kennedy, S., Robbins, J. ve Delorme, F. (2001). The role of fiscal rules in determining fiscal performance. Department of Finance Working Paper, 237-266. 
Kopits, M. G. ve Symansky, M. S. A. (1998). Fiscal policy rules. Washington DC: International Monetary Fund.

Krol, R. (1996). A survey of the impact of budget rules on state taxation, spending and debt. Cato Journal, 16, 295.

Kukk, M. ve Staehr, K. (2015). Enhanced fiscal governance in the European Union: The fiscal compact. Baltic Journal of European Studies, 5(1), 73-92.

Levinson, A. (1998). Balanced budgets and business cycles: Evidence from the states. National Tax Journal, 51(4), 715-732.

Poterba, J. M. (1995). Balanced budget rules and fiscal policy: Evidence from the states. National Tax Journal, 48(3), 329-336.

Poterba, J. M. (1996). Budget institutions and fiscal policy in the US states. The American Economic Review, 86(2), 395-400.

Poterba, J. M. ve Rueben, K. (1999). State fiscal institutions and the US municipal bond market: Fiscal institutions and fiscal performance (ss. 181-208) içinde. ABD: University of Chicago Press.

Schaechter, A., Kinda, T., Budina, N. ve Weber, A. (2012). Fiscal rules in response to the crisistoward the next-generation rules: A new dataset. International Monetary Fund Working Paper, 1-49.

Stansel, D. (1994). Taming leviathan: Are tax and spending limits the answer?. Cato Institute Policy Analysis, 1-26.

Symansky, M. S. A., Debrun, M. X. ve Epstein, N. P. (2008). A new fiscal rule: Should Israel go Swiss?. International Monetary Fund, 8-87.

Wyplosz, C. (2005). Fiscal policy: Institutions versus rules. National Institute Economic Review, 191(1), 64-78. 